\title{
New Earth-abundant Materials for Large-scale Solar Fuels Generation
}

\author{
Rajiv Ramanujam Prabhakar, Wei Cui, and S. David Tilley*
}

\begin{abstract}
The solar resource is immense, but the power density of light striking the Earth's surface is relatively dilute, necessitating large area solar conversion devices in order to harvest substantial amounts of power for renewable energy applications. In addition, energy storage is a key challenge for intermittent renewable resources such as solar and wind, which adds significant cost to these energies. As the majority of humanity's present-day energy consumption is based on fuels, an ideal solution is to generate renewable fuels from abundant resources such as sunlight and water. In this account, we detail our recent work towards generating highly efficient and stable Earth-abundant semiconducting materials for solar water splitting to generate renewable hydrogen fuel.
\end{abstract}

Keywords: Copper oxide $\cdot$ Hydrogen $\cdot$ Photoelectrochemical water splitting $\cdot \mathrm{Sb}_{2} \mathrm{Se}_{3} \cdot$ Solar fuels

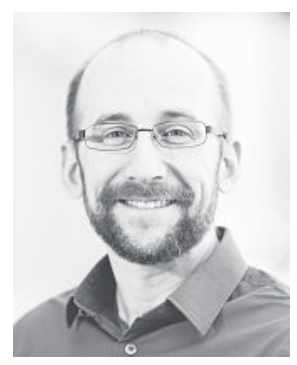

David Tilley received his bachelor's degree in Chemistry from the University of Georgia, USA. He then moved to California to carry out his $\mathrm{PhD}$ studies in the group of Matthew Francis at UC Berkeley. Following a two year post-doctoral research stay at Princeton University in the group of Erik Sorensen, he moved to Switzerland, having obtained a post-doctoral fellowship from the National Science Foundation (USA) to carry out watersplitting research in the group of Prof. Michael Graetzel. After the two-year fellowship was complete, he became a group leader of the water-splitting subgroup in the Graetzel laboratory. In 2015, he moved to the University of Zurich to take up an Assistant Professorship position in the University Research Priority Program Light to Chemical Energy Conversion (URPP LightChEC), with tenure-track in the Department of Chemistry. His current research focuses on thin film inorganic materials for solar water splitting.

\footnotetext{
${ }^{\star}$ Correspondence: Prof. Dr. S. D. Tilley

University of Zurich

Department of Chemistry

Y34 H 24

Winterthurerstrasse 190

$\mathrm{CH}-8057$ Zurich

E-mail: david.tilley@chem.uzh.ch
}

\section{Introduction and Motivation}

I started my undergraduate studies at the University of Georgia in 1998. I had many times participated in a Musical Theatre Camp in my hometown of Cartersville, Georgia, and so I began my studies as a Drama major, thinking I might be a Broadway actor. After one rather uninteresting semester, I quickly decided that this would perhaps be a better hobby than a career. My next idea was to be a medical doctor, and so I was therefore taking the required science curriculum. I had to take the dreaded organic chemistry course, but I found that I actually really liked it. I was attracted to the creativity of synthesis, with finding the most efficient routes to synthesize target molecules. I moved to Berkeley in 2002 to begin my $\mathrm{PhD}$ in the field of chemical biology, which was gaining in popularity at the time. I was part of the group effort to develop site-selective protein modification reactions for new biomaterials, and I pioneered a new method to selectively target the tyrosine residues of proteins using palladium $\pi$-allyl complexes. ${ }^{[1]}$ Towards the end of my $\mathrm{PhD}$, I felt drawn towards more focused synthetic chemistry, and joined the laboratory of Prof. Erik Sorensen at Princeton University as a postdoctoral researcher to further develop my synthetic skills, pursuing a total synthesis of hirsutellone B. ${ }^{[2,3]}$ As I prepared to apply for faculty positions, I wrote proposals that used my skill set in organic synthesis and chemical biology and applied it towards a new and intriguing field: solar energy conversion to fuels. After consulting with my advisors, I decided that another postdoctoral position would be beneficial to really get into such a completely new field, and I applied to the International Research Fellowship Program of the National Science Foundation (USA), where I was awarded a fellowship that allowed me to learn semiconductor-based water splitting in the renowned laboratory of Prof. Michael Graetzel. There, I directed my efforts towards the synthesis of new inorganic materials for solar water splitting to generate hydrogen fuel.

In this account, we highlight a few of the recent results from our laboratory that focus on efficient and stable Earthabundant semiconductor materials, with an eye towards large-scale water splitting.

\section{Antimony Selenide $\left(\mathrm{Sb}_{2} \mathrm{Se}_{3}\right)$}

Antimony selenide is an 'emerging material' for thin film solar cell applications, with efficiencies as high as $6.5 \%$ reported in the literature. ${ }^{[4]}$ With a band gap similar to silicon $(\sim 1.2 \mathrm{eV})$, it is ideal for coupling with a wide band gap photoanode to fabricate a tandem photoelectrochemical cell for unassisted watersplitting applications. ${ }^{[5]}$ With very few reports in the literature for water splitting, p-type $\mathrm{Sb}_{2} \mathrm{Se}_{3}$ was a promising candidate for investigation as a photocathode for $\mathrm{H}_{2}$ evolution. $\mathrm{Sb}_{2} \mathrm{Se}_{3}$ thin films were fabricated in a very simple fashion, by selenization of electrodeposited $\mathrm{Sb}$ metal with elemental selenium at $350{ }^{\circ} \mathrm{C}$ for $40 \mathrm{~min}$ utes in a tube furnace. [6] The $\mathrm{Sb}_{2} \mathrm{Se}_{3}$ thin films obtained were indexed with the orthorhombic phase of $\mathrm{Sb}_{2} \mathrm{Se}_{3}$ with no signs of secondary phases or impurities from the X-ray diffraction patterns. In order to be employed as a photocathode for water splitting applications, the conduction band edge position must lie above the thermodynamic potential for $\mathrm{H}_{2}$ evolution $(0 \mathrm{~V}$ vs RHE). The conduction band position was estimated through a combination of MottSchottky analysis and X-ray photoelectron spectroscopy (XPS) to be approximately 
$-0.4 \mathrm{~V}$ vs RHE, and therefore suitable for use as a photocathode for $\mathrm{H}_{2}$ evolution. Fig. 1a shows the device architecture of the $\mathrm{Sb}_{2} \mathrm{Se}_{3}$ photocathode where an Earthabundant catalyst $(\mathrm{MoS})$ is employed for $\mathrm{H}_{2}$ evolution in $1 \mathrm{M} \mathrm{H}_{2} \mathrm{SO}_{4}$ electrolyte solution under simulated one sun illumina-

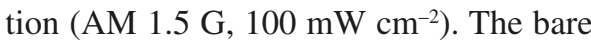
$\mathrm{Sb}_{2} \mathrm{Se}_{3}$ without the $\mathrm{MoS}_{\mathrm{x}}$ catalyst showed negligible photocurrent, whereas the $\mathrm{MoS}_{x}$ catalyst-coated $\mathrm{Sb}_{2} \mathrm{Se}_{3}$ showed photocurrent density as high as $5.2 \mathrm{~mA} \mathrm{~cm}^{-2}$ at 0 $\mathrm{V}$ vs RHE. Gas chromatography measurements confirmed that the large amount of bubbles produced during operation were in fact $\mathrm{H}_{2}$, with $\sim 100 \%$ faradaic efficiency. To improve the photocurrent onset of the $\mathrm{Sb}_{2} \mathrm{Se}_{3}$, a post-sulfurization treatment was performed. This treatment resulted in the formation of a thin antimony sulfide $\left(\mathrm{Sb}_{2} \mathrm{~S}_{3}\right)$ layer, which has an ionization potential higher than the $\mathrm{Sb}_{2} \mathrm{Se}_{3}$, leading to a valence band offset at the $\mathrm{Sb}_{2} \mathrm{~S}_{3} / \mathrm{Sb}_{2} \mathrm{Se}_{3}$ interface. ${ }^{[7]}$ Such an offset should act as a hole blocking layer, which could result in reduced surface recombination. This was reflected in the photoelectrochemical (PEC) performance of a sulfurized photocathode $\left(\mathrm{Sb}_{2} \mathrm{Se}_{3}-\mathrm{MoS}_{\mathrm{x}}-\mathrm{S}\right)$, which exhibited an improved photocurrent onset $(\sim 100 \mathrm{mV}$ earlier) and high photocurrent densities $\left(\sim 14 \mathrm{~mA} \mathrm{~cm}^{-2}\right)$ at $0 \mathrm{~V}$ vs. RHE (Fig. 1b). This improvement was also evident from the incident photon conversion efficiency (IPCE) spectrum, where the sulfurized sample showed high IPCE values across the entire absorption spectrum of $\mathrm{Sb}_{2} \mathrm{Se}_{3}{ }^{[6]}$ It is also noteworthy that the band gap was unaffected by the sulfurization treatment, and STEM-EDX mapping showed that there was no sulfur penetration deep into the $\mathrm{Sb}_{2} \mathrm{Se}_{3}$ film (Fig. 2a). Upon investigating the surface of the sulfurized and non-sulfurized samples by XPS, the $\mathrm{Sb}_{2} \mathrm{O}_{3}$ content decreased after the sulfurization treatment. This oxide layer was partially converted to $\mathrm{Sb}_{2} \mathrm{~S}_{3}$ (confirmed by Raman spectroscopy), which we hypothesize acts as a hole blocking layer at the $\mathrm{Sb}_{2} \mathrm{Se}_{3}$ surface, resulting in an improvement of PEC performance (Fig. 2b and 2c).

$\mathrm{Sb}_{2} \mathrm{Se}_{3}-\mathrm{MoS}_{\mathrm{x}}$ (sulfurized) exhibited a $30 \%$ degradation of photocurrent in the strongly acidic conditions ( $\mathrm{pH} 0$ ) after $2 \mathrm{~h}$ at $0 \mathrm{~V}$ vs RHE under illumination. However, upon re-application of $\mathrm{MoS}_{\mathrm{x}}$ catalyst, the photocurrent density was restored to nearly the initial value. This observation points to a loss of $\mathrm{MoS}_{\mathrm{x}}$ catalyst during operation, which was also confirmed by XPS measurements of both freshly prepared and measured samples that show loss of Mo and $\mathrm{S}$ signal after operation. With a thicker coating of $\operatorname{MoS}_{x}(\sim 30 \mathrm{~nm})$, better photocurrent stabilities were obtained for the non-sulfurized samples (up to $20 \mathrm{~h}$ in $1 \mathrm{M}$ $\mathrm{H}_{2} \mathrm{SO}_{4}$ at $0 \mathrm{~V}$ vs RHE) (Fig. 3a). However,

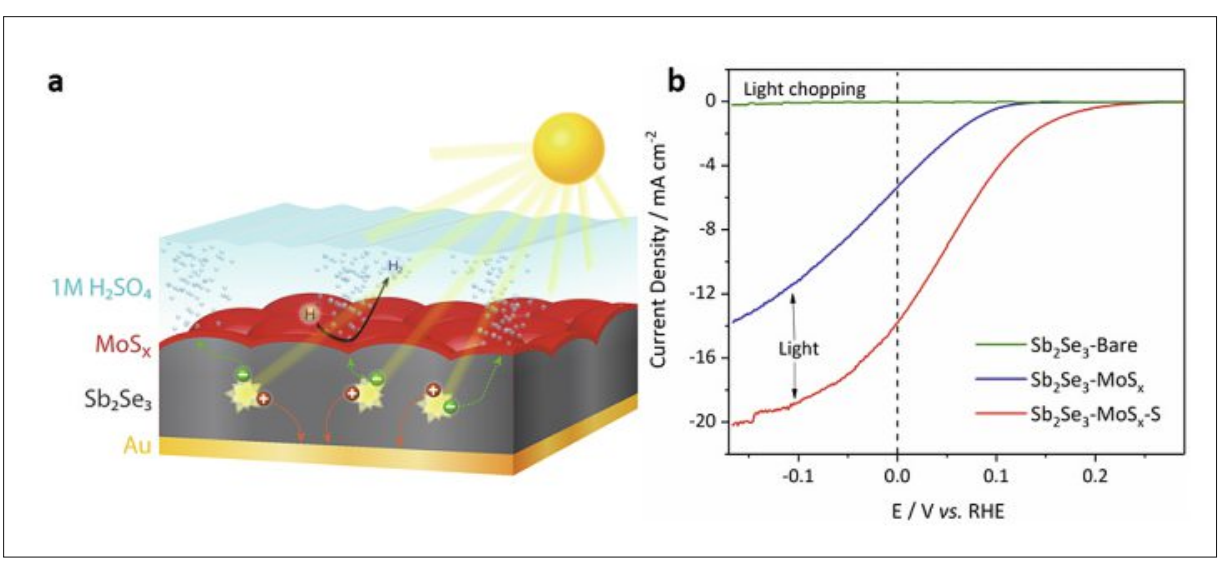

Fig. 1. a) Schematic representation of $\mathrm{Sb}_{2} \mathrm{Se}_{3}-\mathrm{MoS}_{x}$ photocathode. b) Current density-potential characteristics of bare $\mathrm{Sb}_{2} \mathrm{Se}_{3}$ (light chopping), $\mathrm{Sb}_{2} \mathrm{Se}_{3}-\mathrm{MoS}_{\mathrm{x}}$ (non-sulfurized), $\mathrm{Sb}_{2} \mathrm{Se}_{3}-\mathrm{MoS}_{\mathrm{x}}-\mathrm{S}$ (sulfurized) in $1 \mathrm{M} \mathrm{H}_{2} \mathrm{SO}_{4}$ under simulated one sun illumination. Reproduced from J. Mater. Chem. A 2017, 5, 23139 with permission of the Royal Society of Chemistry.

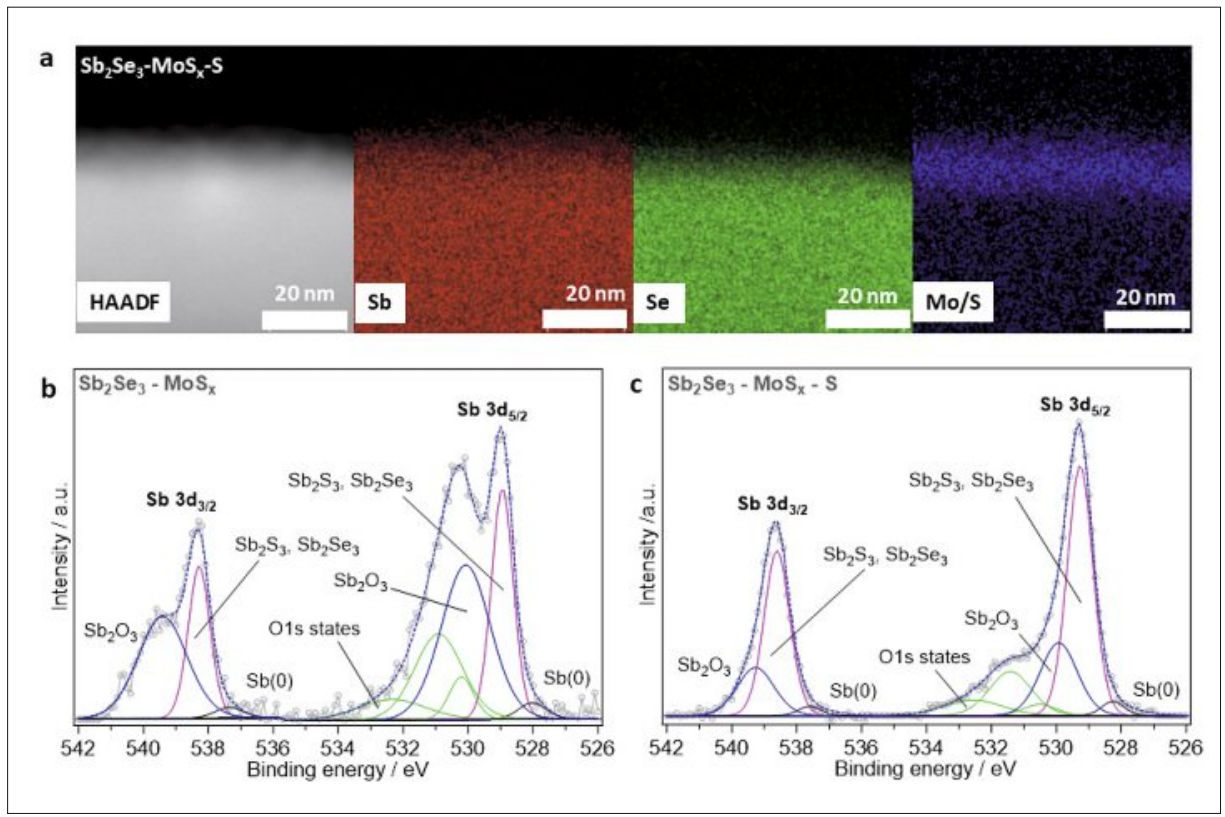

Fig. 2. a) STEM HAADF image and EDX elemental mapping of $\mathrm{Sb}_{2} \mathrm{Se}_{3}-\mathrm{MoS}_{\mathrm{x}}-\mathrm{S}$ (sulfurized). b) XPS core level spectrum of $\mathrm{Sb} 3 \mathrm{~d}$ for $\mathrm{Sb}_{2} \mathrm{Se}_{3}-\mathrm{MoS}_{\mathrm{x}}$ (non-sulfurized). c) XPS core level spectrum of $\mathrm{Sb}$ $3 d$ for $\mathrm{Sb}_{2} \mathrm{Se}_{3}-\mathrm{MoS}_{\mathrm{x}}-\mathrm{S}$ (sulfurized). Reproduced from J. Mater. Chem. A 2017, 5, 23139 with permission of the Royal Society of Chemistry.

the high-performing sulfurized sample slowly degraded to nearly $0 \mathrm{~mA} \mathrm{~cm}{ }^{-2}$ after $20 \mathrm{~h}$. To identify the origin of this performance loss, a dark electrolysis experiment of $\mathrm{MoS}_{\mathrm{x}}$ on glassy carbon electrode was performed, which showed that the $\mathrm{MoS}_{\mathrm{x}}$ catalyst slowly degraded to nearly $0 \mathrm{~mA}$ $\mathrm{cm}^{-2}$ after $20 \mathrm{~h}$, again pointing to a problem of the catalyst. In this case, the degradation of the $\operatorname{MoS}_{x}$ catalyst could be attributed to conversion of the $\mathrm{MoS}_{\mathrm{x}}$ to $\mathrm{MoO}_{\mathrm{x}}$, which results in reduced catalytic activity of the catalyst. ${ }^{[8]}$ The XPS spectra before and after showed a large increase in the oxygen content of the $\mathrm{MoS}_{\mathrm{x}}$ catalyst surface after $20 \mathrm{~h}$ operation. These investigations suggest that the instability of the $\mathrm{Sb}_{2} \mathrm{Se}_{3}-$ MoS $-\mathrm{S}$ photocathode is primarily due to the $\mathrm{MoS}_{\mathrm{x}}$ catalyst and not to the $\mathrm{Sb}_{2} \mathrm{Se}_{3}$. To confirm the intrinsic stability of the $\mathrm{Sb}_{2} \mathrm{Se}_{3}$ thin film, a photocorrosion stress test was performed where the bare $\mathrm{Sb}_{2} \mathrm{Se}_{3}$ film was subjected to 285 cyclic voltagrams in $1 \mathrm{M}$ $\mathrm{H}_{2} \mathrm{SO}_{4}$ under one sun illumination during a $4.75 \mathrm{~h}$ experiment (Fig. 3b). After this stress test $\operatorname{MoS}_{\mathrm{x}}$ catalyst was deposited, and the sample exhibited similar PEC performance to the typically prepared $\mathrm{Sb}_{2} \mathrm{Se}_{3}-$ $\mathrm{MoS}_{\mathrm{x}}$ samples. This important finding shows that $\mathrm{Sb}_{2} \mathrm{Se}_{3}$ is intrinsically stable to photocorrosion in strong acid (in contrast to other high efficiency photocathodes), and is therefore a strong candidate for practical, large-scale PEC water splitting.

\section{Copper Oxides}

An alternative strategy to finding materials that are intrinsically stable in the harsh 


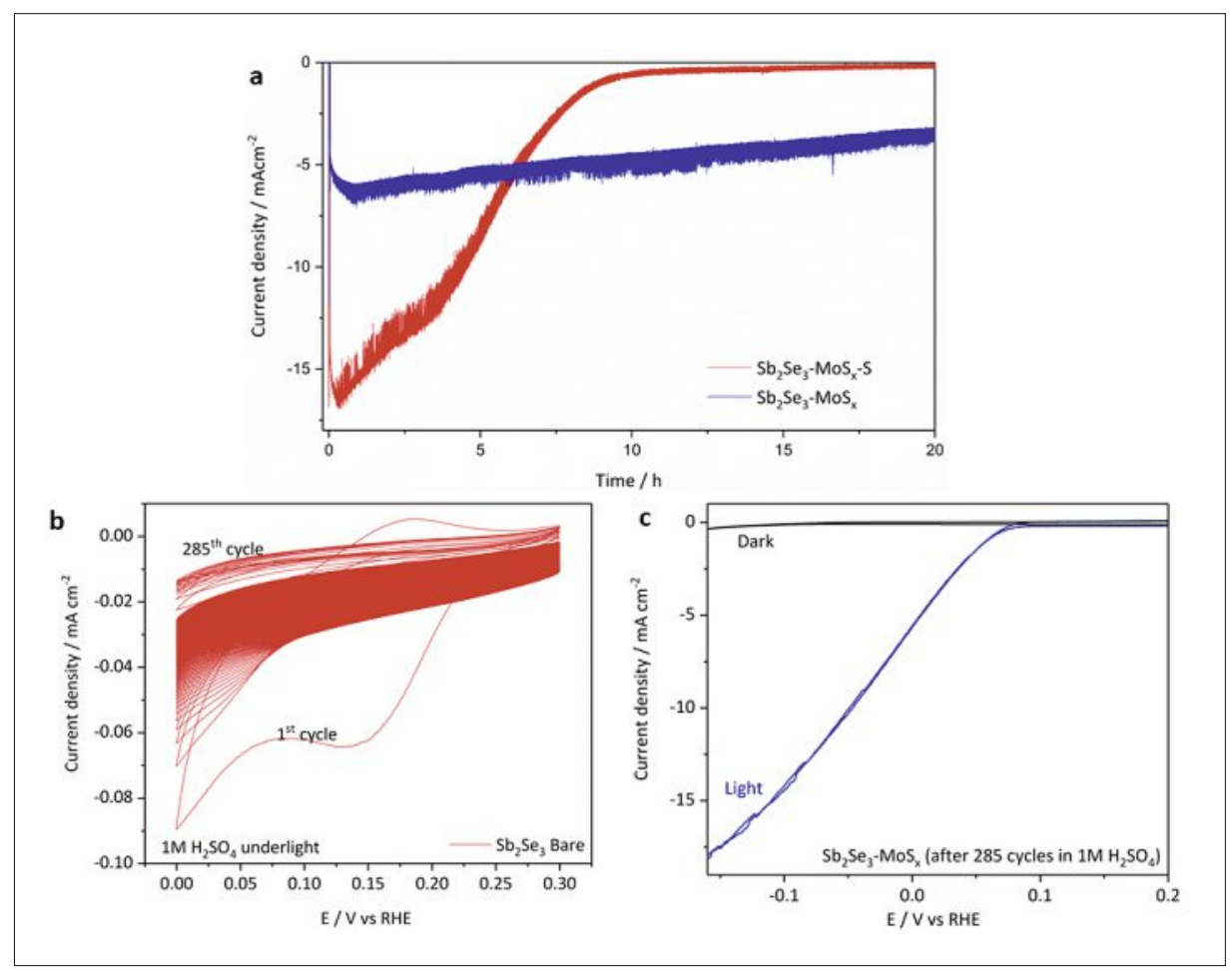

Fig. 3. a) Current density vs. time plots for $\mathrm{Sb}_{2} \mathrm{Se}_{3}-\mathrm{MoS}_{x}$ and $\mathrm{Sb}_{2} \mathrm{Se}_{3}-\mathrm{MoS}_{x}-\mathrm{S}(\sim 30 \mathrm{~nm} \mathrm{MoS}$ thickness) in $1 \mathrm{M} \mathrm{H}_{2} \mathrm{SO}_{4}$ at $0 \mathrm{~V} v$ s. RHE at one sun illumination $\left(100 \mathrm{~mW} \mathrm{~cm}^{-2}\right)$. b) $\mathrm{CV}$ of a bare $\mathrm{Sb}_{2} \mathrm{Se}_{3}$ thin film (without $\mathrm{MoS}_{x}$ catalyst) in $1 \mathrm{M} \mathrm{H}_{2} \mathrm{SO}_{4}$ under 1 sun illumination $\left(100 \mathrm{~mW} \mathrm{~cm}{ }^{-2}\right)$. The sweep rate was $10 \mathrm{mV} \mathrm{s}^{-1}$ and the total experiment time was $4.75 \mathrm{~h}$. c) Current density vs. potential plots of a $\mathrm{Sb}_{2} \mathrm{Se}_{3}-\mathrm{MoS}_{x}$ photocathode prepared after $285 \mathrm{CV}$ cycles of bare $\mathrm{Sb}_{2} \mathrm{Se}_{3}$ in $1 \mathrm{M} \mathrm{H}_{2} \mathrm{SO}_{4}$ under one sun illumination. Reproduced from J. Mater. Chem. A 2017, 5, 23139 with permission of the Royal Society of Chemistry.

electrolyte solutions of water splitting is to use transparent, conductive protective layers that block access of the electrolyte to the light-absorbing material underneath, while enabling light and photogenerated charge carriers to pass. When using such coating layers, the power producing junction is located underneath the surface, while the protective layer/electrolyte interface is Ohmic in nature, resulting in a so-called 'buried' photovoltaic junction. In this situation, one needs only consider the band positions of the photoabsorber with respect to the overlayer or partner material (e.g. a $\mathrm{p}-\mathrm{n}$ junction) in order to maximize the voltage, and therefore improve the onset potential for water splitting.

\subsection{Cupric Oxide (CuO)}

$\mathrm{CuO}$ is an Earth-abundant p-type semiconductor with an optical absorption spectrum (band gap 1.4-1.7 eV) ideally suited for harvesting a significant portion of the solar spectrum. ${ }^{[9]}$ By coupling with a $2 \mathrm{eV}$ photoanode, for instance, a tandem PEC cell with over $15 \%$ efficiency could be achieved. ${ }^{[5]}$ However, one of the main drawbacks is the photocorrosion of $\mathrm{CuO}$ in the presence of protons. There are many reports in the literature with $\mathrm{CuO}$ as a photocathode, but it is unclear how much of the photocurrent corresponds to hydrogen evolution. In our work, we addressed the issue of photocorrosion of $\mathrm{CuO}$ by protecting it with a $\mathrm{TiO}_{2}$ overlayer, and improved the PEC performance using a suitable n-type buffer layer. $\mathrm{CuO}$ thin films were prepared in a simple fashion by annealing electrodeposited $\mathrm{Cu}$ metal using a two-step annealing process $\left(600{ }^{\circ} \mathrm{C}\right.$ in $\mathrm{Ar}$ atmosphere for $1 \mathrm{~h}$ and $600{ }^{\circ} \mathrm{C}$ in air for $2 \mathrm{~h}) .{ }^{[10]}$ This process yielded films with large grains and better sample homogeneity, which resulted in more reproducible PEC performance. First, the bare $\mathrm{CuO}$ photocathode without any buffer or protection layers was investigated under one sun illumination in $\mathrm{pH} 7$ phosphate buffer. Photocathodic currents as high as $1.16 \mathrm{~mA}$ $\mathrm{cm}^{-2}$ were obtained at potentials of $\sim 0.4$ $\mathrm{V}$ vs RHE, and an onset of dark current at $0.25 \mathrm{~V}$ vs RHE was observed, indicating photocorrosion of the $\mathrm{CuO}$ (Fig. 4a). After applying a fixed bias of $0 \mathrm{~V}$ vs RHE under constant illumination, the photocurrent rapidly decreased due to the corrosion of $\mathrm{CuO}$ to $\mathrm{Cu}$ metal (Fig. 4b). Initially, $\mathrm{TiO}_{2}$ was employed both as a protective and buffer layer for $\mathrm{CuO}$, which showed poor PEC performance (Fig. 4c). However, when $\mathrm{CdS}$ was employed as a buffer layer, the PEC performance improved significantly. Photocurrent densities of $\sim 1.4 \mathrm{~mA}$ $\mathrm{cm}^{-2}$ were obtained at $0 \mathrm{~V}$ vs RHE, and a champion device provided a photocurrent density of $1.6 \mathrm{~mA} \mathrm{~cm}^{-2}$. It is also evident that the dark current was significantly reduced upon deposition of the $\mathrm{TiO}_{2}$ overlayer, due to prevention of the photocorrosion of the $\mathrm{CuO}$ layer. The protection strategy enabled a stable photocurrent density over a period of $1 \mathrm{~h}$ at $0 \mathrm{~V}$ vs RHE under one sun illumination, and the photocurrent obtained was confirmed to be $\mathrm{H}_{2}$ evolution from gas chromatography experiments. In order to gain a better understanding of the electrical properties of the $\mathrm{CuO}$ absorber, Mott-Schottky analysis was performed and the carrier density was estimated. The acceptor density was found to be very high, on the order of $10^{21} \mathrm{~cm}^{-3}$, which can be attributed to a large number of copper vacancies. The high doping results in a very narrow space-charge region, which limits the charge collection efficiency. This was also reflected in the IPCE spectrum of the $\mathrm{CuO}$ photocathode where the low energy photons (> $650 \mathrm{~nm}$ ) absorbed deeper in the film were not able to be extracted due to the short diffusion length of the photoelectrons. Therefore, optimization of the $\mathrm{CuO}$ synthesis or doping could help reduce the acceptor density and hence improve the carrier collection length of $\mathrm{CuO}$ photocathodes, which would pave the way for higher PEC performance.

\subsection{Cuprous Oxide $\left(\mathrm{Cu}_{2} \mathrm{O}\right)$}

Cuprous oxide, a p-type semiconductor with a band gap of $2.0 \mathrm{eV}$, is a promising Earth-abundant material for hydrogen evolution photocathodes. Theoretically, a large photocurrent density of $14.7 \mathrm{~mA}$ $\mathrm{cm}^{-2}$ can be achieved under one sun illumination. ${ }^{[11]}$ To solve the poor stability issue of $\mathrm{Cu}_{2} \mathrm{O}$ in aqueous media, pioneering work was carried out by the Graetzel group who developed a multilayer composite photocathode consisting of a buried $\mathrm{p}-\mathrm{n}$ junction $\left(\mathrm{p}-\mathrm{Cu}_{2} \mathrm{O}\right.$ and $\mathrm{n}$ $\mathrm{ZnO}$ or $\mathrm{n}-\mathrm{AZO}$ ), a $\mathrm{TiO}_{2}$ protective layer, and a surface hydrogen evolution catalyst. Photocurrents as high as $7.6 \mathrm{~mA} \mathrm{~cm}^{-2}$ were obtained at $0 \mathrm{~V}$ vs RHE, however, the onset potential was still relatively negative $(\sim 0.5$ $\mathrm{V}$ vs RHE).[12] This results from the small photovoltage generated by the buried $\mathrm{p}-\mathrm{n}$ junction, which usually gives $\sim 0.5 \mathrm{~V}$ open circuit voltage $\left(\mathrm{V}_{\mathrm{oc}}\right)$ in the corresponding photovoltaic devices. ${ }^{[13]}$ In this view, an ultrathin $\mathrm{Ga}_{2} \mathrm{O}_{3}$ layer was applied to replace the $\mathrm{ZnO}$ or AZO layer. Due to the more favorable band alignment, a very positive onset potential was observed by $\mathrm{Li}$ and co-workers (1.02 V vs RHE) as well as a photocurrent of $2.95 \mathrm{~mA} \mathrm{~cm}^{-2}$ at $0 \mathrm{~V}$ vs RHE. [14]

Recently, we fabricated a thermallyoxidized $\mathrm{Cu}_{2} \mathrm{O}$ based photocathode (TO$\left.\mathrm{Cu}_{2} \mathrm{O}\right),{ }^{[15]}$ which is schematically illustrated in Fig. 5. After the thermal oxidation of copper foil, $\mathrm{Ga}_{2} \mathrm{O}_{3}$ and $\mathrm{TiO}_{2}$ layers were subsequently deposited on the front side 
of the foil by the atomic layer deposition (ALD) technique. Next, a thin Au layer was coated on the back side to serve as the back contact, and connected with a $\mathrm{Cu}$ wire. After coating with an electrodeposited $\mathrm{RuO}_{x}$ catalyst, this $\mathrm{TO}-\mathrm{Cu}_{2} \mathrm{O}$ photocathode exhibits an onset potential of 0.9 $\mathrm{V}$ vs RHE and large photocurrents even at substantially positive potential (e.g. 3.5 $\mathrm{mA} \mathrm{cm}{ }^{-2}$ at $0.5 \mathrm{~V}$ vs RHE) in $\mathrm{pH} 5$ electrolyte.

Previous work in photovoltaics have already shown that $\mathrm{TO}-\mathrm{Cu}_{2} \mathrm{O}$ has a more effective absorption and better conversion of photons from the green and red part of the solar spectrum, compared to the widely used $\mathrm{Cu}_{2} \mathrm{O}$ by electrodeposition $\left(\mathrm{ED}-\mathrm{Cu}_{2} \mathrm{O}\right)$. Therefore, we designed a dual $\mathrm{Cu}_{2} \mathrm{O}$ photocathode by coupling a front transparent $\mathrm{ED}-\mathrm{Cu}_{2} \mathrm{O} / \mathrm{Ga}_{2} \mathrm{O}_{3} / \mathrm{TiO}_{2} /$ $\mathrm{RuO}$ photocathode with a back $\mathrm{TO}-\mathrm{Cu}_{2} \mathrm{O} /$ $\mathrm{Ga}_{2} \mathrm{O}_{3} / \mathrm{TiO}_{2} / \mathrm{RuO}$ photocathode, as shown in Fig. 6. With optimized thicknesses of each $\mathrm{Cu}_{2} \mathrm{O}$ layer, this dual $\mathrm{Cu}_{2} \mathrm{O}$ photocathode configuration showed an enhanced photocurrent density of $3.67 \mathrm{~mA}$ $\mathrm{cm}^{-2}$ at $0.5 \mathrm{~V}$ vs RHE, and a new record energy conversion efficiency of $1.9 \%$ at around $+0.45 \mathrm{~V}$ vs RHE, as shown in Fig. $7 \mathrm{a}$. The enhanced photocurrents at low applied bias are of great significance for the developing of high efficiency tandem cells. The IPCE curve of this dual photocathode is presented in Fig. 7b, together with those of the individual front ED and back TO$\mathrm{Cu}_{2} \mathrm{O}$ photocathodes. The TO- $\mathrm{Cu}_{2} \mathrm{O}$ photocathode has much stronger conversion near the $\mathrm{Cu}_{2} \mathrm{O}$ band edge $(500-620 \mathrm{~nm})$ than the ED sample, while the ED- $\mathrm{Cu}_{2} \mathrm{O}$ photocathode shows better use of the blue light $(<450 \mathrm{~nm})$, enabling efficient photon conversion over the entire absorption spectrum of $\mathrm{Cu}_{2} \mathrm{O}$.

\section{Perspective and Outlook}

Photoelectrochemical water splitting is a promising route to large-scale renewable hydrogen production. Unlike alternative technologies such as photovoltaic-coupled electrolysis, the integrated PEC approach allows smart thermal management that increases the overall device efficiency, as the electrolyte cools the irradiated photoabsorber-enabling a larger output photovoltage-while the increased temperature of the electrolyte improves the efficiency of the electrocatalytic fuel generation reaction. ${ }^{[16]}$ However, in order to be cost competitive with photovoltaic-coupled electrolysis, improvements in the efficiency and stability of the PEC cells must be obtained, which is a significant challenge. The strategy of using protective layers to stabilize intrinsically unstable materials enables any photovoltaic material to be used, including high-

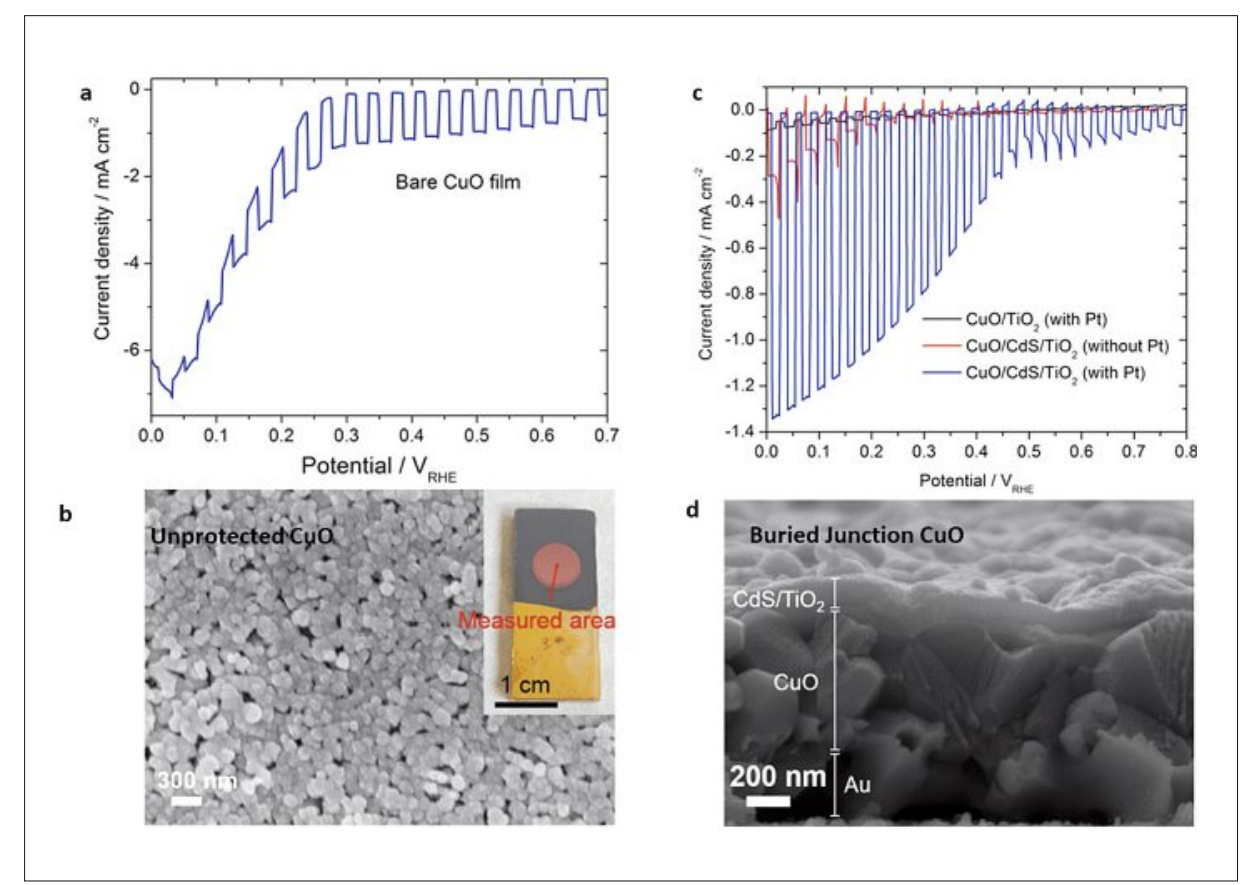

Fig. 4. a) Current density-potential curve of unprotected bare $\mathrm{CuO}$ in $1 \mathrm{M}$ phosphate buffer (pH 7) under one sun illumination. b) Plan view SEM image of unprotected $\mathrm{CuO}$ after measurement at $0.4 \mathrm{~V}$ vs RHE for 30 min. c) Current density-potential curves of $\mathrm{CuO} / \mathrm{TiO}_{2}$ (with $\mathrm{Pt}$ ) and $\mathrm{CuO} / \mathrm{CdS} /$ $\mathrm{TiO}_{2}$ with and without Pt-catalyst measured in $1 \mathrm{M}$ phosphate buffer $\left(\mathrm{pH}^{2} 7\right)$ under chopped illumination from simulated one sun illumination. d) Cross-sectional SEM images of the $\mathrm{CuO} / \mathrm{CdS} / \mathrm{TiO}_{2}$ photocathode. Reproduced from ref. [10] with permission. Copyright (2017) American Chemical Society.

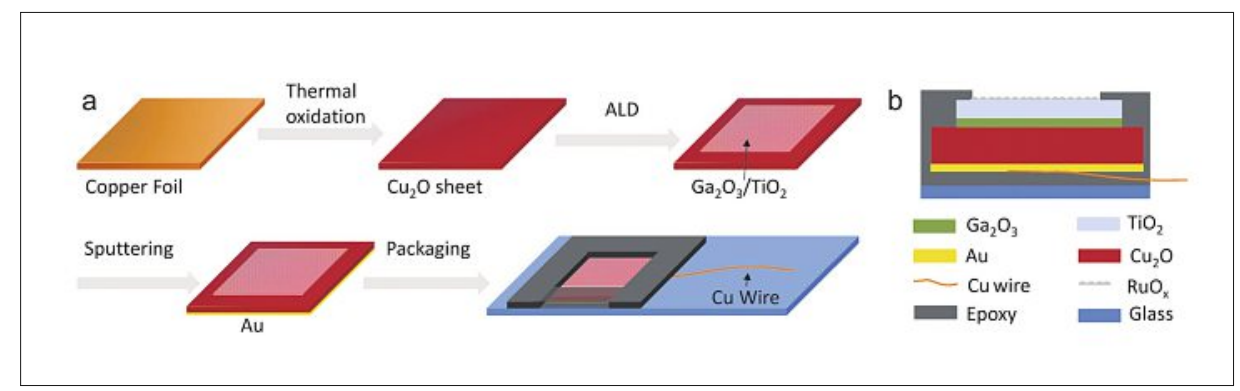

Fig. 5. a) Procedure for fabrication of the TO- $\mathrm{Cu}_{2} \mathrm{O}$ photocathode. b) Cross-section view of the photocathode (not to scale). Reproduced from ref. [15] with permission from Wiley.

ly developed photovoltaic materials such as silicon, which would normally corrode in the harsh electrolyte solution. Although some examples in the literature have demonstrated weeks of stability, it remains uncertain whether this strategy will be suitable for the years of stability that are required. Ideally, new materials will be found that are both highly efficient and intrinsically stable without the need for protective layers. $\mathrm{Sb}_{2} \mathrm{Se}_{3}$ is a promising candidate, as it is resistant to photocorrosion in $1 \mathrm{M} \mathrm{H}_{2} \mathrm{SO}_{4}$ and gives very high hydrogen-producing photocurrents under strong electrical bias. The photovoltage of this material must be improved, however, which is a current topic of research in our group.

\section{Acknowledgements}

The authors gratefully acknowledge funding from the University of Zurich, the University

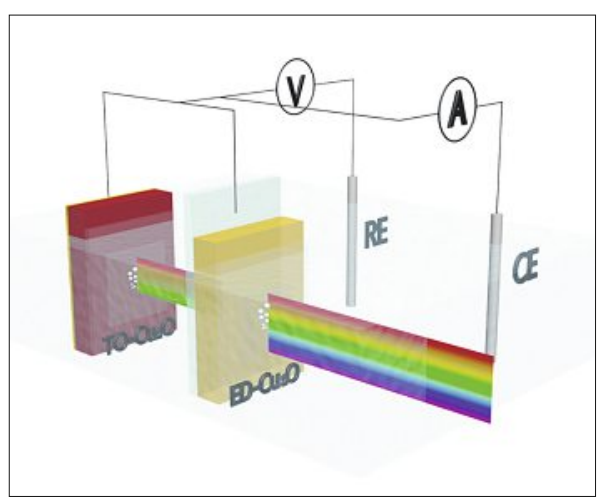

Fig. 6. Schematic diagram of the dual $\mathrm{Cu}_{2} \mathrm{O}$ photocathode experiment. The transparent electrodeposited $\left(E D-\mathrm{Cu}_{2} \mathrm{O}\right)$ photocathode is placed in front of the thermally oxidized (TO$\mathrm{Cu}_{2} \mathrm{O}$ ) photocathode, enabling efficient photon conversion over the entire absorption spectrum. Reproduced from ref. [15] with permission from Wiley. 
Research Priority Program LightChEC, and the Swiss National Science Foundation (AP Energy Grant \# PYAPP2 160586).

Received: March 2, 2018

[1] S. D. Tilley, M. B. Francis, J. Am. Chem. Soc. 2006, 128,1080

[2] S. D. Tilley, K. P. Reber, E. J. Sorensen, Org. Lett. 2009, 11, 701.

[3] K. P. Reber, S. D. Tilley, C. A. Carson, E. J. Sorensen, J. Org. Chem. 2013, 78, 9584

[4] C. Chen, L. Wang, L. Gao, D. Nam, D. Li, K. Li, Y. Zhao, C. Ge, H. Cheong, H. Liu, H. Song, J. Tang, ACS Energy Lett. 2017, 2, 2125.

[5] M. S. Prévot, K. Sivula, J. Phys. Chem. C 2013, 117,17879

[6] R. R. Prabhakar, W. Septina, S. Siol, T. Moehl, R. Wick-Joliat, S. D. Tilley, J. Mater. Chem. A 2017, 5, 23139.

[7] M. A. Tumelero, R. Faccio, A. A. Pasa, J. Phys. Chem. C 2016, 120, 1390.

[8] E. Parzinger, B. Miller, B. Blaschke, J. A. Garrido, J. W. Ager, A. Holleitner, U. Wurstbauer, ACS Nano 2015, 9, 11302

[9] B. K. Meyer, A. Polity, D. Reppin, M. Becker, P. Hering, P. J. Klar, T. Sander, C. Reindl, J. Benz, M. Eickhoff, C. Heiliger, M. Heinemann, J. Bläsing, A. Krost, S. Shokovets, C. Müller, C. Ronning, Phys. status solidi 2012, 249, 1487.

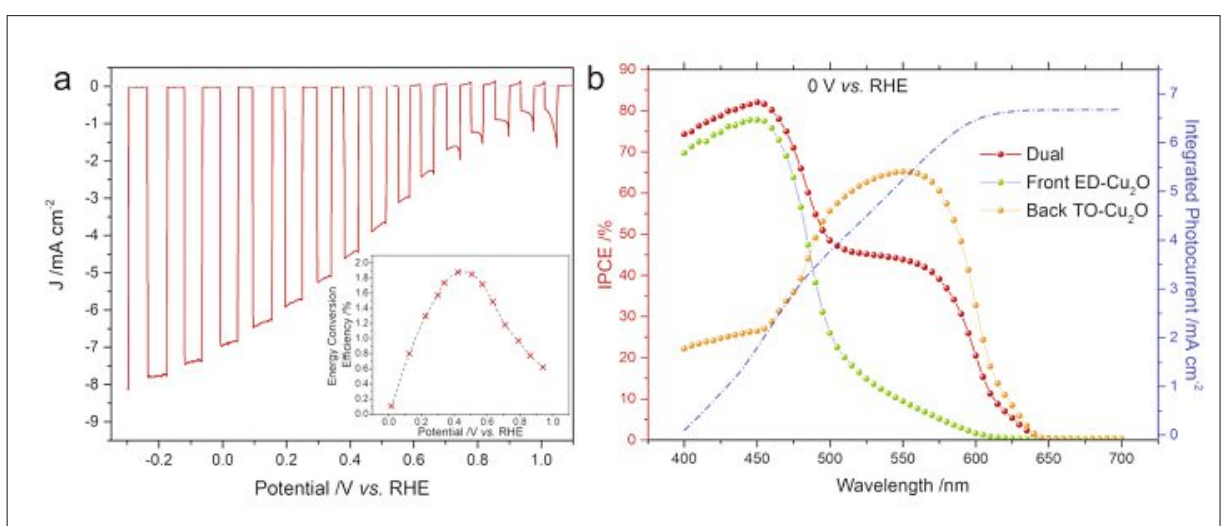

Fig 7. a) The PEC and b) IPCE of the dual $\mathrm{Cu}_{2} \mathrm{O}$ photocathode. Inset of a) is the thermodynamically-based energy conversion efficiency. Reproduced from ref. [15] with permission from Wiley.

[10] W. Septina, R. R. Prabhakar, R. Wick, T. Moehl, S. D. Tilley, Chem. Mater. 2017, 29, 1735

[11] A. Paracchino, N. Mathews, T. Hisatomi, M. Stefik, S. D. Tilley, M. Grätzel, Energy Environ. Sci. 2012, 5, 8673 .

[12] A. Paracchino, V. Laporte, K. Sivula, M. Grätzel, E. Thimsen, Nat. Mater. 2011, 10, 456.

[13] R. Wick, S. D. Tilley, J. Phys. Chem. C 2015, $119,26243$.
[14] C. Li, T. Hisatomi, O. Watanabe, M. Nakabayashi, N. Shibata, K. Domen, J.-J. Delaunay, Energy Environ. Sci. 2015, 8, 1493.

[15] W. Niu, T. Moehl, W. Cui, R. Wick-Joliat, L. Zhu, S. D. Tilley, Adv. Energy Mater. 2018, 8, 1702323.

[16] S. Tembhurne, S. Haussener, J. Electrochem. Soc. 2016, 163, H988. 